\title{
Monitoring Adverse Effects of Antipsychotics and Antidepressants: A Population Based Study
}

\author{
Satya Sree Rallabandi', Sai Samanth Makula', Vasudeva Murthy Sindgi ${ }^{2}$, Bandari Jagadeesh Babu², \\ Usha Sree Puneem ${ }^{1, *}$
}

${ }^{1}$ Department of Pharmacy Practice, Jayamukhi College of Pharmacy (Affiliated to Kakatiya) University, Warangal, Telangana, INDIA. 2Department of Pharmacology, Jayamukhi College of Pharmacy (Affiliated to Kakatiya) University, Warangal, Telangana, INDIA.

\begin{abstract}
Aim: To monitor the nature and incidences adverse effects of both antipsychotics and antidepressants medicines in the psychiatry outpatient department. Objectives: Reporting the incidences of adverse effects and to establish the frequency of a specific class of drug. Identifying the system affected and the assessment of the management of the adverse effects by the physician. For the study, we have adopted Global Assessment Scale (GAS), Simpson-Angus Extra pyramidal Side Effects Scale (SAS) and The Antidepressant Side-Effect Checklist (ASEC). Materials and Methods: A prospective cohort study carried out in the psychiatry out-patient department. All the patients attending psychiatry outpatient department enrolled based on the pre-specified inclusion criteria and monitored for adverse effects. Causality also assessed by WHO-UMC causality assessment system and Naranjo Causality Assessment. Results: The incidence rate of adverse effects (46.07\%) and 560 adverse effects documented. Weight gain $(n=29,9.2 \%)$ followed by drowsiness $(n=27,4.82 \%)$ are most commonly reported adverse effects. Atypical antipsychotics $(n=279,49.82 \%)$ were the most common class of psychotropic drugs implicated in adverse effects. Escitalopram $(n=93,37.80 \%)$ followed by olanzapine $(n=53,21.54 \%)$ associated with a maximum number of adverse effects. Central nervous system $(n=225,40.17 \%)$ was the most affected organ system followed by gastrointestinal system $(n=130,23.21 \%)$. Conclusion: Study revealed moderate incidences of adverse effects in patients attending the psychiatry outpatient department. Majority of the adverse effects reported during the study were mild in nature and not preventable. The role of a clinical pharmacist clearly elucidated regular intensive monitoring of adverse effects may improve the quality of patients' care, reduction in the treatment cost and augmentation of the medication adherence among patients.
\end{abstract}

Key words: Adverse effects, Pharmacovigilance, Antipsychotics, Antidepressants, Extra pyramidal side effects.

\section{INTRODUCTION}

According to WHO, Adverse drug reaction is defined as "a response to a drug that is noxious and unintended and occurs at doses normally used in the man for the prophylaxis, diagnosis or therapy of disease, or for modification of physiological function." ${ }^{1}$ Adverse effects of antipsychotics and antidepressants range from mild forms such as nausea, headache to most severe forms like sudden coma and cardiac death. Extra pyramidal side effects of antipsychotics are (akathisia, tardive dyskinesia) devastating to the extent that could restrict the patients from continuing the medication. Adverse effects (AE) of drugs used in psychiatric care occur at minimum doses prescribed and are one of the leading causes of morbidity and mortality in health care system and more than two million serious adverse drug reactions occurring yearly. Studies conducted on hospitalized patient populations assess that $6.7 \%$ of hospitalized patients have a serious adverse drug reaction with a fatality rate of $0.32 \% .^{2}$ The cost of drug-related morbidity and mortality is $\$ 136$ billion annually, that is more than the total cost of cardiovascular or diabetic care. ${ }^{3}$ Furthermore one of the five injuries or deaths per hospitalized patient are due to ADRs. ${ }^{4}$ In India, to monitor the adverse events and their burden on patients, Government launched a National Pharmacovigilance Programme $(\mathrm{NPvP})$, after the failure of regional centres of WHO Programme for International Drug Monitoring. ${ }^{5}$
DOI: 10.5530/ijopp.14.3.38

Address for correspondence: Dr. Usha Sree Puneem Department of Pharmacy Practice, Jayamukhi College of Pharmacy (Affiliated to Kakatiya) University, Warangal - 506009, Telangana, INDIA.

Phone no: +91-6303673570 Email Id: ushasree.puneem@ gmail.com

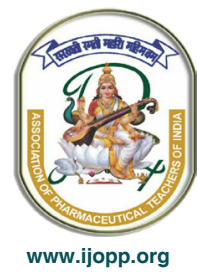


In the present study, we identified the incidence of adverse effects of antipsychotics and antidepressants. Adverse effects are categorised according to the major class of drugs causing AE's, spectrum of AE's and organ systems affected. Antecedent to adverse effects noticed and causing the patients' non-adherent to their medication. Causality assessed using WHO-UMC causality assessment system and Naranjo Causality Assessment.

\section{MATERIALS AND METHODS}

The main objective was to determine the incidence of AE's in patients attending Psychiatric Department of Jayakrishna Psychiatric Care and Counselling Center, Warangal (U), India and to assess the physician in the management of the AE's. Secondary objective was to determine the frequency of adverse effects in a specific drug class and to categorize them according to the organs affected. This prospective cohort study employed to review the adverse effects. A total number of 176 patients were included during the study period.

Patients adept enough to read and write and the caretakers attended the patient at least once a week for one hour provided a consent form and took approval to participate in the study. In contrast to that, illiterate patients or caretakers with verbal consent. The patient was included in the study only after obtaining the consent of his/her participation. The study was approved by Institutional review board (Approval number- 14353D1006 / JCP/ IRB/2018/07).

\section{Recruitment}

The patients provided forms to fill with details about the AE's experienced by them. If the patient is mentally ill to the extent that he/she cannot read or understand the scales mentioned in forms entrusted with caretakers. In contrast, if the patients or caretakers cannot understand the scales containing questions with reference to AEs, conversed by the study conductor to record the data. The study included a sample of 176 subjects and conducted for a period of six months from March 2018 to August 2018.

\section{Study Population}

Patients of both genders, all age groups and diagnosed with a psychiatric disorder according to The Diagnostic and Statistical Manual of Mental Disorders-IV and experiencing at least one adverse effect are part of the study. Patients receiving at least one antipsychotic or antidepressant medication during the study period were also included in the study. In contrast, patients who are not receiving an antipsychotic or antidepressant medications and patients experiencing adverse effects due to medication error or experiencing symptoms due to withdrawal and mentally ill patients who failed to describe their conditions excluded from the study.

\section{Study Material}

Patient profile form used to collect the details. Standard scales are used to document the adverse effects included the following: Glasgow Antipsychotic Side-effect Scale (GASS); Simpson-Angus Extra pyramidal Side Effects Scale and The Antidepressant side effect checklist (ASEC).

\section{Study Procedure}

Patients' details recorded in the data collection forms. To record experienced adverse effects patients are provided with different scales. All the adverse effects reported by the patients, caretakers and observed by the consulting physician documented.

The documented adverse effects classified according to the type of psychiatric disorder, class of drugs, spectrum of adverse effects, organ systems affected; Incidence of adverse effects and causality assessment.

\section{RESULTS}

Patients $(N=382)$ screened for the adverse effects during their visit to the hospital throughout the study period of six months (March, 2018 to August, 2018), from which 176 patients were found to be experiencing at least one adverse effect. The overall incidence of adverse effects observed to be $46.07 \%$. The schizophrenic patients $(n=85,48.29 \%)$ and patients affected with depression $(\mathrm{n}=91,51.70 \%)$ included for our final analysis of the study. Antipsychotics adverse effects outnumbered $(314,56.07 \%)$ the antidepressants $(246,43.92 \%)$ adverse effects.

Prevalence of the Adverse effects in female patients $(n=103,58.5 \%)$ is higher than male $(73,41.4 \%)$. Majority of the patients who were treated by antipsychotics or antidepressants were in the age group of 25-50 years $(n=111,63.0 \%)$ followed by the age group below 25 years $(n=38,21.7 \%)$ and less affected age group observed in above 50 years $(n=27,15.3 \%)$. The incidence of disease manifestation in rural patients $(n=94,53.40 \%)$ is slightly higher than urban patients $(n=82,46.59 \%)$. Distressing events considerably found to be the root cause in patients $(n=133,75.56 \%)$ and no preceding event in rest of the patients $(n=43,24.43 \%)$. Patients $(n=68,38.6 \%)$ were included regardless of their duration of disorder observed below 1 to 5 years followed by with psychiatric 
illness $(n=41,23.29 \%)$ with more than 5 years. In this study the $129(73.2 \%)$ patients' on monotherapy and patients on polytherapy constituted $26.7 \%(n=47)$. Larger part of the patients $(n=137,77.84 \%)$ identified with good adherence to the medication and non-adherence was noticed in $22.15 \%(n=39)$ of the patients.

Atypical antipsychotics accounted for 49.82\% (279) and prescribed frequently. Typical antipsychotics are less prescribed $(35,6.25 \%)$ out of 560 adverse effects. Antidepressants used in the patients' attended also constituted a major part of the total adverse effects. The different antidepressants like Selective Serotonin Reuptake Inhibitors (SSRI's) (178, 31.78\%), Serotonin Norepinephrine Reuptake Inhibitors (SNRI's) (26, 4.64\%), aminoketone $(6,1.07 \%)$ and tetracyclic antidepressants $(36,6.42 \%)$ prescribed. Drugs associated with adverse effects mentioned in Table 1 and AntipsychoticsSpectrum of Major Adverse Effects and Drug(s) Implicated mentioned in Table 2.

During the study, olanzapine $(n=27)$ caused a high frequency of adverse effects $(53,9.46 \%)$ followed by lurasidone $(n=19)$ which accounted for $9.28 \%$ (52). The next preferred drug prescribing in the atypical antipsychotics is aripiprazole $(n=14)$ and the resulted in $36(6.42 \%)$ adverse effects. Risperidone and amisulpride are the prescribed in equal number of patients $(n=12)$ and the adverse effects reported by them are $34(6.07 \%)$ and $36(6.42 \%)$ respectively. The least prescribed drugs are in the order of ziprasidone $(n=11)$, trifluoperazine $(n=6)$, quetiapine $(n=6)$, clozapine $(n=5)$, haloperidol $(n=4)$ and chlorpromazine $(n=2)$; and the number of adverse effects reported by their use is $37(6.60 \%), 21(3.75 \%), 28(5 \%)$, $17(3.03 \%), 8(1.42 \%), 6(1.07 \%)$ respectively. From nine different types of antidepressants used in the treatment during the study period, escitalopram $(n=36)$ is the most prescribed drug, due to its highest safety profile and its use approved even in the pregnancy. The study noticed in escitalopram prescribed patients, the frequencies of adverse effects are 93 (16.60\%). The next commonly prescribed antidepressants are sertraline, mirtazapine and fluoxetine. Prescribed in 12 patients each for all three drugs categories and the number of adverse effects reported by them are 35(6.25\%), 36(6.42\%), 30(5.35\%) respectively. The least prescribed drugs are paroxetine (8 times) with number of adverse effects of $16(2.85 \%)$, desvenlafaxine (6 times) with adverse effects of 12 $(2.14 \%)$, duloxetine (4 times) with 14(2.5\%) adverse effects. Bupropion (2 times) and fluvoxamine (one time) caused adverse effects at a rate of $6(1.07 \%)$ and $4(0.71 \%)$ respectively.

From all the adverse effects reported from antipsychotics in patients, weight gain $(29,9.2 \%)$ was dominant, followed by frequency of drowsiness is 27 and with orthostatic hypotension 26 . The average pre and post treatment weight change was $3 \mathrm{~kg}$ with olanzapine ( $15 \mathrm{mg}, 30$ days) and $2 \mathrm{~kg}$ per month with lurasidone and aripiprazole each. Atypical antipsychotics are the most commonly implicated psychotropic drugs in weight gain followed by Selective Serotonin Reuptake Inhibitors (21, 8.53\%). The most commonly involved antidepressants in weight gain are mirtazapine followed by escitalopram and fluoxetine.

Dry mouth $(24,9.75 \%)$ was the next most encountered adverse effect with antidepressants. Tremor (23, 4.10\%) is also a majorly documented adverse effect due to antipsychotics. Headache accounted in 21 patients $(8.53 \%)$ with antidepressants. Normal sleep architecture disturbed in patient's treatment with antidepressants. In the current study insomnia reported in $14(5.69 \%)$ patients and in escitalopram $(n=6)$ followed by sertraline

Table 1: Drugs associated with adverse effects.

\begin{tabular}{cc} 
Name of the Drug & $\begin{array}{c}\text { No. of Adverse Effects (\%) } \\
\mathbf{N}=314(\%)\end{array}$ \\
\hline Olanzapine & $53(21.54)$ \\
Lurasidone & $52(21.13)$ \\
Ziprasidone & $37(15.04)$ \\
Aripiprazole & $36(14.63)$ \\
Risperidone & $34(13.82)$ \\
Quetiapine & $28(11.38)$ \\
Amisulpride & $22(8.94)$ \\
Trifluoperazine & $21(8.53)$ \\
Clozapine & $17(6.91)$ \\
Haloperidol & $8(3.25)$ \\
Chlorpromazine & $6(2.43)$ \\
Escitalopram & $93(37.80)$ \\
Mirtazapine & $36(14.63)$ \\
Sertaline & $35(14.22)$ \\
Fluoxetin & $30(12.19)$ \\
Paroxetin & $16(6.50)$ \\
Duloxetin & $4(1.69)$ \\
Besvenlafaxine &
\end{tabular}


$(n=5)$ and paroxetine $(n=2)$ are the most common drugs caused insomnia (Table 3).

Due to anticholinergic effects of antidepressants constipation $(17,6.91 \%)$ and urinary retention and incontinence $(6,2.43 \%)$ observed in patients with both side effects noticed with escitalopram and mirtazapine. Abnormal gait $(n=16,5.09 \%)$, akathisia $(n=144,45 \%)$, tardive dyskinesia $(n=4,1.27 \%)$ and fatigue $(n=2$, $2.14 \%$ ) experienced by the patients on typical and atypical antipsychotics. Sweating and yawning due to antidepressants were found with equal frequency of 13 $(5.28 \%)$ and primary drugs involved are escitalopram $(n=6)$ and fluoxetine $(n=3)$.

Sialorrhea is also a major adverse effect that interferes

Table 2: Antipsychotics- Spectrum of Major Adverse Effects and Drug(s) Implicated.

\begin{tabular}{|c|c|c|}
\hline Type of AE's & $\begin{array}{c}\text { Frequency } \\
(\mathrm{N}, \%) \text { (Total } \\
\text { AEs }=314)\end{array}$ & Drugs Implicated \\
\hline Weight Gain & $29(9.2)$ & $\begin{array}{l}\text { Olanzapine }(n=6) \\
\text { Lurasidone }(n=5) \\
\text { Aripiprazole }(n=4)\end{array}$ \\
\hline Drowsiness & $27(4.82)$ & $\begin{array}{l}\text { Olanzapine }(n=6) \\
\text { Lurasidone }(n=5) \\
\text { Aripiprazole }(n=5)\end{array}$ \\
\hline $\begin{array}{l}\text { Orthostatic } \\
\text { Hypotension }\end{array}$ & $26(8.28)$ & $\begin{array}{l}\text { Olanzapine }(n=6) \\
\text { Lurasidone }(n=4) \\
\text { Aripiprazole }(n=3)\end{array}$ \\
\hline Tremors & $23(4.10)$ & $\begin{array}{l}\text { Olanzapine }(n=3) \\
\text { Aripiprazole }(n=3) \\
\text { Ziprasioe }(n=2)\end{array}$ \\
\hline Abnormal Gait & $16(5.09)$ & $\begin{array}{l}\text { Lurasidone }(n=3) \\
\text { Risperidone }(n=2) \\
\text { Ziprasidone }(n=2)\end{array}$ \\
\hline Akathisia & $14(4.45)$ & $\begin{array}{l}\text { Lurasidone }(n=4) \text {; } \\
\text { Aripiprazole }(n=3) \text {; } \\
\text { Olanzapine }(n=2)\end{array}$ \\
\hline Fatigue & $12(2.14)$ & $\begin{array}{l}\text { Lurasidone }(n=3) \\
\text { Quetiapine }(n=2) ; \\
\text { Risperidone }(n=2)\end{array}$ \\
\hline Sialorrhea & $08(1.42)$ & $\begin{array}{c}\text { Risperidone }(n=3) \\
\text { Clozapine }(2) \\
\text { Olanzapine }(n=1)\end{array}$ \\
\hline Sexual Dysfunction & 05 (1.59) & $\begin{array}{l}\text { Lurasidone }(n=2) \\
\text { Clozapine }(n=1) \\
\text { Quetiapine }(n=1)\end{array}$ \\
\hline Tardive Dyskinesia & $04(1.27)$ & $\begin{array}{c}\text { Trifluoperazine }(n=2) \\
\text { Quetiapine }(n=1)\end{array}$ \\
\hline & & Olanzapine $(n=1)$ \\
\hline Hyperprolactinemia & $02(0.63)$ & $\begin{array}{l}\text { Risperidone }(n=1) \\
\text { Haloperidol }(n=1)\end{array}$ \\
\hline
\end{tabular}

with the daily activity of a patient. In the current study sialorrhea reported in eight patients followed by risperidone $(n=3)$, clozapine $(n=2)$ and olanzapine $(n=1)$. Hyperprolactinemia $(n=2,0.63 \%)$ due to decreased dysinhibition of prolactin levels in the infundibular tract leading to sexual dysfunction $(n=5,1.59 \%)$ also remain as major factor contributing to medication non-adherence. These effects are mostly encountered with lurasidone $(n=2)$, risperidone, clozapine, haloperidol and quetiapine with a less frequency $(n=1)$.

Coming to the involvement of organ system, central and peripheral nervous system ( $225 \mathrm{AEs}, 40.17 \%$ ) was found to be the most effected system; the next most affected system is gastrointestinal system with $130(23.21 \%)$ adverse effects. The common adverse effects include nausea, vomiting, constipation and diarrhoea. Followed by GI system, cardiovascular adverse effects (60 AEs, $10.71 \%$ ) were more profound as most of the drugs have action on adrenergic and cholinergic receptors and causing disturbances in the normal cardiac rhythm and palpitations.

Metabolic $(n=55,9.82 \%)$ and reproductive systems are affected $(n=21,3.75 \%)$. The interference of these drugs with sexual life is very common and involves a number of effects. Urinary system $(n=26,4.64 \%)$ abnormalities were seen in patients with both antipsychotic and antidepressant treatment. Musculoskeletal system (fatigue) was reported in 14 patients $(2.5 \%)$ and is considered as a movement disorder. Ophthalmology is the least affected system with a patient population of $n=13(2.32 \%)$. An endeavour was made to manage the adverse effects with co-prescribing antimuscarinic agent trihexyphenidyl, reducing the dose and switching to other antipsychotics or antidepressants. Management and outcomes of the adverse effects mentioned in Table 4 and flow chart of the antipsychotics and antidepressants adverse effects in the patients mentioned in Figure 1.

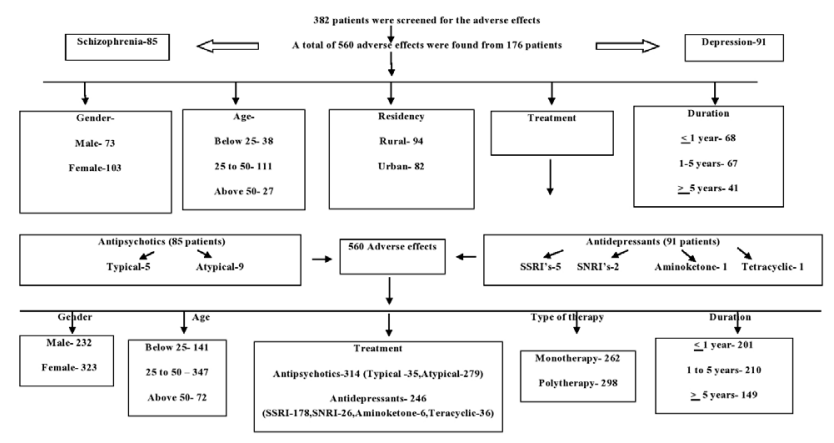

Figure 1: Flow chart of the antipsychotics and antidepressants adverse effects in the patients.

Indian Journal of Pharmacy Practice, Vol 14, Issue 3, Jul-Sep, 2021 
Table 3: Antidepressants- Spectrum of Major Adverse Effects and Drug (s)

Implicated.

\begin{tabular}{|c|c|c|}
\hline Type of AE's & $\begin{array}{c}\text { Frequency } \\
(\mathrm{N}, \%)(\text { Total AEs }=246)\end{array}$ & Drugs Implicated \\
\hline Dry Mouth & $24(9.75)$ & $\begin{array}{l}\text { Escitalopram }(n=10) \text {; Mirtazapine }(n=5) \\
\text { Fluoxetine }(n=3)\end{array}$ \\
\hline Headache & $21(8.53)$ & Escitalopram $(n=9)$; Fluoxetine $(n=3)$; Sertraline $(n=3)$ \\
\hline Weight Gain & $21(8.53)$ & $\begin{array}{l}\text { Mirtazapine }(n=8) \text {; Escitalopram }(n=4) \\
\text { Fluoxetine }(n=2)\end{array}$ \\
\hline Constipation & $17(6.91)$ & Escitalopram $(n=7)$; Mirtazapine $(n=3)$ \\
\hline Insomnia & $14(5.69)$ & $\begin{array}{l}\text { Escitalopram }(n=6) \text {; Sertraline }(n=5) \\
\text { Paroxetine }(n=2)\end{array}$ \\
\hline Sweating & $13(5.28)$ & Escitalopram(n=6);Fluoxetine $(n=3)$ \\
\hline Yawning & $13(5.28)$ & $\begin{array}{l}\text { Escitalopram( } n=6) ; \text { Mirtazapine }(n=2) \text {; Sertraline } \\
\qquad(n=1)\end{array}$ \\
\hline $\begin{array}{l}\text { Orthostatic } \\
\text { Hypotension }\end{array}$ & $09(3.65)$ & Escitalopram(n=4); Mirtzapine(n=2) \\
\hline $\begin{array}{l}\text { Problems in } \\
\text { Urination }\end{array}$ & $06(2.43)$ & Mirtazapine $(n=2)$; Escitalopram $(n=1)$ \\
\hline Blurred Vision & $04(1.62)$ & $\begin{array}{l}\text { Escitalopram(n=2); Paroxetine Drugs Implicated } \\
\qquad(n=2)\end{array}$ \\
\hline $\begin{array}{c}\text { Sexual } \\
\text { Dysfunction }\end{array}$ & $03(1.21)$ & Sertraline $(n=2)$; Duloxetin $(n=1)$ \\
\hline
\end{tabular}

\section{Table 4: Outcome of Adverse Effects.}

\begin{tabular}{|c|c|}
\hline Outcome & No. of Patients (\%), $n=176$ \\
\hline \multicolumn{2}{|c|}{ Management of Adverse Effects } \\
\hline $\begin{array}{l}\text { Management with anti- } \\
\text { muscarinic }\end{array}$ & $58(32.95)$ \\
\hline Dose altered & $74(42.04)$ \\
\hline No change in the treatment & $44(25)$ \\
\hline \multicolumn{2}{|c|}{ Outcome of Adverse Effect } \\
\hline Fatal & 00 \\
\hline Recovery & $76(43.18)$ \\
\hline $\begin{array}{c}\text { Continuing the same } \\
\text { treatment }\end{array}$ & $23(13.06)$ \\
\hline Partial Improvement & $30(17.04)$ \\
\hline Unknown & $47(26.70)$ \\
\hline
\end{tabular}

\section{Causality Assessment}

WHO- UMC causality assessment system- majority of the adverse effects were classified as possible (220, $39.28 \%)$ and probable $(124,22.14 \%)$. In a certain category, 38 (6.78\%) and least number of adverse effects $(22,3.92 \%)$ observed in unclassifiable category. Naranjo Causality Assessment Scale showed that the majority of the adverse effects were of the possible $(204,36.42 \%)$ and probable $(178,31.78 \%)$ type. Definite type were (42, $7.5 \%)$, followed by doubtful $(36,6.42 \%)$. Some of the adverse effects were not categorized due to lack of time for the patients, disease severity and the lack of awareness. During the study period, tinnitus was observed in a patient on treatment with amisulpiride and lurasidone, which was managed with drug discontinuation. In a bipolar patient on treatment with sodium valproate, skin rash was noted after three days of treatment found to be an acute hypersensitivity syndrome and managed with drug discontinuation.

\section{DISCUSSION}

Monitoring the adverse effects of anti psychotics and anti depressants for their accurate detection, classification and management, have the relevance in the clinical and research stance. This prospective cohort study systematically investigated using various strategies to record and report the adverse effects occurred during the study and the assessment and management of the AEs. 
The incidence rate of adverse effects in the study was found to be $46.07 \%$, in contrast to the many international studies which were observed to be $5.01 \%-19.8 \%{ }^{6,7}$ However, in another study it was established to the extent of $61.1 \% .{ }^{8}$ Weight gain was the most commonly implicated ADR in the present study. Many ADR related studies reported weight gain as one of the most commonly observed in patients taking a certain class of psychotropic medications. ${ }^{9,10}$ However, Switching to an antipsychotic with lower propensity for weight gain seems to be a good strategy to blunt the metabolic effects, but no randomized trials have yet been conducted, and no SGA is absolutely free from metabolic consequences. ${ }^{11}$

Drowsiness was the second most commonly found adverse effect in the present study. However, a few studies have reported tremor as the most commonly noted ADR followed by weight gain. ${ }^{11,12}$ Difference in the findings could be due to the difference in the prescribing pattern of medications and the type of psychiatric patients visiting the Out Patient Department (OPD) as reported in other ADR monitoring studies. In some studies observed that drowsiness is one of the main reasons for discontinuation of medication. ${ }^{13}$

CNS adverse effects such as sedation, insomnia and headache are common with psychotropics as drugs acts on CNS. Many research articles revealed sedation or somnolence as the common adverse effect. It is documented that sedation persists for the first few months, but usually wears off and does not require any management such as reducing the dose or switching to other drugs. ${ }^{14}$

Even though Extra Pyramidal Symptoms (EPS) are observed less frequently with atypical antipsychotics, long-term use has shown some patients experiencing tardive dyskinesia and akathisia. ${ }^{15}$ Several meta-analyses, most comparing Second Generation Antipsychotics (SGA) with haloperidol, have shown that SGAs are less likely to cause extra pyramidal symptoms. However, recent studies comparing SGAs with lower potency First Generation Antipsychotics (FGA) have not shown this difference. ${ }^{16}$ Gastrointestinal adverse effects indicated next to the Central and Peripheral nervous system. Nausea or vomiting, diarrhoea and constipation were the most reported adverse effects of this system. As these effects are transient and remain for short time, physical morbidity and risk of non-adherence not observed.

A particular focus on risks and benefits is warranted among people with prevalent CVD because these patients seem to have the highest risks associated with APs. ${ }^{17}$ Recent studies shows SNRIs are associated with an increased incidence of cardiovascular AEs, especially hypertension. ${ }^{18}$ Thus in patients with existing cardiovascular diseases should not be prescribed with SNRI's. In this study, metabolic and cardiovascular systems equally affected and patients monitored for serious adverse effects such as ECG changes and lipid profile.

In the present study anticholinergic effects such as urinary incontinence or retention and dry mouth were also reported and they found to be decreasing the quality of life of most patients leading to medication non-adherence. Switching of the drugs and managing these adverse effects with other drugs were found to be effective. Hyperprolactinemia and sexual dysfunction were other deteriorating adverse effects reported major antipsychotics and antidepressants. Presence of osteoporosis, sexual side effects, or prolactin dependent breast cancer may necessitate switching to an antipsychotic that does not raise prolactin levels, such as aripiprazole or quetiapine. ${ }^{19}$

In the present study, we noticed five patients out of 52 , stopped their medication on their own at home after the development of ADR. This observation supports the fact that ADR might lead to non-adherence or discontinuation of therapy.

\section{LIMITATIONS}

The main limitation of the present study was the short duration of the study period. Study duration of more than one year could be more beneficial in identifying the wide spectrum of $\mathrm{ADR}$ to a wide variety of medications. In addition, majority of the ADRs identified during the study period were mild in nature. No fatal/serious ADRs were reported or documented in the outpatient clinic, as the patients who develop serious ADRs admitted to emergency room directly followed by inpatient department. Re-challenging was not possible for the majority of the ADRs.

\section{CONCLUSION}

There is limited data regarding the prescribing pattern related to the adverse effects and their management in the current area of the study, thus by monitoring the adverse effects. For the assessment and management of AEs, physician's role in the management of adverse effects is desirable along with counselling the patients managing at home with life-style modifications and other non-pharmacological therapy. The role of a clinical pharmacist seems to be higher when compared to other paramedics. A skilled clinical pharmacist will also be 
engaged in psychotherapy regarding the disease course, course of treatment, drug-adverse effects, ruling out drug-interactions, importance of medication adherence, life-style modifications and providing moral support for both patients and their caretakers. This shows the importance of a clinical pharmacist in the department/ area of psychiatry. Regular intensive monitoring of adverse effects in the psychiatry outpatient department by a clinical pharmacist might help in early detection of adverse effects and reduce the risk caused by them and thereby it may improve the quality of care, reduction in the treatment cost and enhancement of medication adherence pattern among patients.

\section{ACKNOWLEDGEMENT}

Authors are grateful to Dr. B. Jagadeesh Babu, for utilising the services of the Jayakrishna Psychiatric Care and Counselling Centre, Hanamkonda, Warangal (U).

\section{CONFLICT OF INTEREST}

The authors declare no conflict of interest.

\section{ABBREVIATIONS}

WHO: World Health Organisation; AE: Adverse Effect; ADR: Adverse Drug Reaction; DSM: Diagnostic and Statistical Manual of Mental Disorders; FGA: First Generation Antipsychotics; SGA: Second Generation Antipsychotics; UMC: Uppsala Monitoring Centre; SSRI: Selective Serotonin Reuptake Inhibitor; SNRI: Serotonin Norepinephrine Reuptake Inhibitor; EPS: Extra Pyramidal Symptoms.

\section{SUMMARY}

This prospective study is about the major adverse effects that are being responsible for non-adherence and reduced therapeutic outcome of both antipsychotics and antidepressants. This study has resulted in the improvement of overall patient care.

\section{REFERENCES}

1. World Health Organization. International drug monitoring: the role of national centres. Report of a WHO meeting. World Health Organ Tech Rep Ser. 1972;498:1-25. PMID 4625548.

2. Lazarou J, Pomeranz $\mathrm{BH}$, Corey $\mathrm{PN}$. Incidence of adverse drug reactions in hospitalized patients: A meta-analysis of prospective studies. JAMA. 1998;279(15):1200-5. doi: 10.1001/jama.279.15.1200, PMID 9555760 .

3. Johnson JA, Bootman JL. Drug-related morbidity and mortality. A cost-of-illness model. Arch Intern Med. 1995;155(18):1949-56, PMID 7575048.

4. Leape LL, Laird BT N, Lawthers AG, Localio AR, Barnes BA et al. The nature of adverse events in hospitalized patients. Results of the Harvard Medical Practice Study II. N Engl J Med 1991; 324(6):377-384.

5. Naman M, Singh K, Kanase H, Pharmacovigilance Programme of India. The beginning, current status and recent progress. Adv Pharmacoepidemiol Drug Saf. 2017;06(04).

6. Solanke B, Mahatme MS, Dakhale G, Hiware S, Shrivastava M, Waradkar P. Adverse drug reaction profile at psychiatry out-patient department of a tertiary referral centre in Central India. Int J Basic Clin Pharmacol. 2013;2(3):341-3. doi: 10.5455/2319-2003.ijbcp20130623.

7. Mishra S, Swain TR, Mohanty M. Adverse drug reaction monitoring of antidepressants in the psychiatry outpatients department of a tertiary care teaching hospital. J Clin Diagn Res. 2013 Jun;7(6):1131-4. doi: 10.7860/ JCDR/2013/4985.3041, PMID 23905119.

8. Lucca JM, Varghese NA, Ramesh M, Ram D. Economic impact and severity of adverse drug reactions in patients with mental illness: A prospective observational study. Int J Health Allied Sci. 2017;6:93-8.

9. Bobes J, Rejas J, Garcia-Garcia M, Rico-Villademoros F, García-Portilla MP, Fernández I, Hernández G, EIRE Study Group. Weight gain in patients with schizophrenia treated with risperidone, olanzapine, quetiapine or haloperidol: results of the EIRE study. Schizophr Res. 2003;62(1-2):77-88. doi: 10.1016/ s0920-9964(02)00431-0, PMID 12765747.

10. Kim SH, Ivanova O, Abbasi FA, Lamendola CA, Reaven GM, Glick ID. Metabolic impact of switching antipsychotic therapy to aripiprazole after weight gain: A pilot study. J Clin Psychopharmacol. 2007;27(4):365-8. doi: 10.1097/ JCP.0b013e3180a9076c, PMID 17632220.

11. Pisano S, Catone G, Veltri S, Lanzara V, Pozzi M, Clementi E, luliano R, Riccio MP, Radice S, Molteni M, Capuano A, Gritti A, Coppola G, Milone A, Bravaccio C, Masi G. Update on the safety of second generation antipsychotics in youths: a call for collaboration among paediatricians and child psychiatrists. Ital J Pediatr. 2016;42(1):51. doi: 10.1186/s13052-016-0259-2, PMID 27209326.

12. Sengupta G, Bhowmick S, Hazra A, Datta A, Rahaman M. Adverse drug reaction monitoring in psychiatry out-patient department of an Indian teaching hospital. Indian J Pharmacol. 2011;43(1):36-9. doi: 10.4103/0253-7613.75664, PMID 21455419.

13. Schorr SG, Loonen AJ, Brouwers JR, Taxis K. A Cross-sectional study of prescribing patterns in chronic psychiatric patients living in sheltered housing facilities. Int J Clin Pharmacol Ther. 2008;46(3):146-50. doi: 10.5414/cpp46146, PMID 18397686.

14. Taylor D, Paon C, Kapur S, editors. The Maudsley prescribing guidelines. 10th ed. Vol. 202. London: Informa Healthcare; 2009. p. 96-7.

15. Piparva KG, Buch JG, Chandrani KV. Analysis of adverse drug reactions of atypical antipsychotic drugs in psychiatry OPD. Indian J Psychol Med. 2011;33(2):153-7. doi: 10.4103/0253-7176.92067, PMID 22345840.

16. Muench J, Hamer AM. Adverse effects of antipsychotic medications. Am Fam Physician. 2010;81(5):617-22. PMID 20187598.

17. Sahlberg M, Holm E, Gislason GH, Køber L, Torp-Pedersen C, Andersson C. Association of selected antipsychotic agents with major adverse cardiovascular events and noncardiovascular mortality in elderly persons. J Am Heart Assoc. 2015;4(9):e001666. doi: 10.1161/JAHA.114.001666, PMID 26330335.

18. Ferguson JM. SSRI antidepressant medications: adverse effects and tolerability. Prim Care Companion J Clin Psychiatry. 2001;3(1):22-7. doi: 10.4088/pcc. v03n0105, PMID 15014625.

19. Haddad PM, Wieck A. Antipsychotic-induced hyperprolactinaemia: mechanisms, clinical features and management. Drugs. 2004;64(20):2291-314. doi: 10.2165/00003495-200464200-00003, PMID 15456328. 